\title{
Dynamic 1D Model of an Active Magnetic Regenerator: A Parametric Investigation
}

\author{
Giulio Tagliafico ${ }^{1}$ - Federico Scarpa*,2 - Luca Antonio Tagliafico ${ }^{2}$ \\ 1 University of Genoa, DCCI, Italy \\ 2 University of Genoa, DIPTEM/TEC, Italy
}

A one dimensional dynamic model of a reciprocating active reciprocating magnetic regenerator (AMR) was developed and a parametric analysis of its behavior at near room temperature conditions was carried out. The investigation is focused on the thermal behavior of the regenerator alone, regardless of the apparatus in which it could work. The parametric investigation aims at evaluating the influence on the AMR performances of the operating frequency and fluid mass flow rate, that is the parameters that can be tuned in a given actual device. The performance parameters analyzed are refrigeration capacity, temperature span, coefficient of performance and second law thermodynamic efficiency. A standard geometry of the AMR was assumed, while the results are given in a non-dimensional form with reference to a conventional operating condition.

Simulations show that the refrigeration capacity is very sensitive to the utilization factor, that causes a $20 \%$ refrigeration capacity reduction with a variation of $-20 \%$ or $+10 \%$. The coefficient of performance $(C O P)$ is poorly influenced by $\Phi$. Frequency variations induce a linear variation in refrigeration capacity, and a decrease in COP due to friction in the intermediate fluid. The second law thermodynamic efficiency trends show that friction and heat transfer irreversibility dominates at low and high temperature spans, respectively.

(C)2011 Journal of Mechanical Engineering. All rights reserved.

Keywords: magnetic refrigeration, active regeneration, modelization, parametric investigation

\section{INTRODUCTION}

Magnetic refrigeration is an innovative and alternative way of cooling at room temperature that promises to be competitive with actual refrigeration techniques, and to guarantee a primary energy saving. Exhaustive reviews on this topic can be found in Engelbrecht et al. [1], Gschneidner and Pecharsky [2], Yu et al. [3].

The AMR is the core of magnetic refrigeration cycles at room temperature, so reliable numerical models that can predict its performance over a wide range of operating conditions are required. There are basically two different approaches in modeling an AMR.

1) The one-dimensional schematization requires the determination of the heat transfer coefficient $h$ between solid and fluid and of the friction factor $f$ that describes the pressure drop in the fluid flow due to viscosity. This approach is followed by Engelbrecht et al. [4] who solves the "steady state" condition, Kawanami [5], Sarlah and
Poredos [6], Bouchekara et al. [7], Risser et al. [8], Tagliafico et al. [9] who solve the time evolution of the temperatures.

2) The two-dimensional schematization can be based on the solution of the continuity, momentum and energy equations in the fluid domain, and of the Fourier's equation in the solid domain, even if only in simple geometries. This approach is followed by Petersen et al. [10], Legait et al. [11] Nielsen et al. [12], who developed and investigated over a wide range of conditions a $2 \mathrm{D}$ model of an AMR made of a stack of parallel plates of gadolinium. For complex, disordered geometries the 1D model approach must be followed in any case. A comprehensive review on AMR models can be found in Nielsen et al. [13] .

The AMR performance are mainly influenced by the thermophysical and magnetothermal properties of the active magnetocaloric material (MCM) employed and the operating temperature. Other effects derive from MCM

*Corr. Author's Address: University of Genoa, DIPTEM/TEC, 
shape, regenerator geometry, fluid mass flow rate and cycle frequency. In this paper, an ideal 1D numerical model of an AMR is presented and employed to evaluate the influence on performance of the parameter that can be tuned in a given device (that is fluid mass flow rate and cycle frequency).

\section{THE NUMERICAL MODEL}

AMR process is based on a four-step regenerative cycle with the aim of amplifying the adiabatic temperature change amplitude given by the magnetocaloric effect by several times. This aim is accomplished by means of an intermediate fluid and a proper synchronization between magnetic field changes and fluid flow. Starting from in isothermal condition, a magnetic field is applied to the solid-based regenerator (magnetization) with a consequent sudden temperature increase in the solid. The fluid is then forced from one side of the regenerator to the other and it warms up cooling the solid (hot blow). The magnetic field is then removed with a temperature drop in the solid (demagnetization). The fluid is forced in the direction opposite to the hot blow and it cools warming up the solid (cold blow). A longitudinal temperature gradient arises along the regenerator that amplifies the adiabatic temperature change of the material.

The model describes in detail only the thermal behavior of the regenerator. The fluid loop is not considered and the heat exchangers outward facing are accounted for by fixing the two inlet temperatures that represent the boundary conditions on the AMR. The magnetization and demagnetization process is described by an instantaneous and reversible adiabatic temperature change, $\Delta T_{a d}$, in the magnetocaloric material.

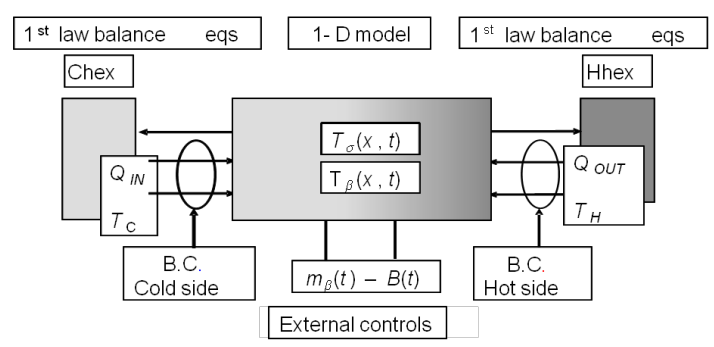

Fig. 1. Conceptual scheme of the AMR model
The AMR model is based on a system of PDEs that gives the temperature fields of both the solid and the fluid. The magnetic field $B(t)$ and the fluid mass flow rate $m_{\beta}(t)$ are imposed as external controls. Fig. 1 shows the scheme of the numerical configuration.

The numerical model consists in the energy balance equation for a differential volume of both the solid and the fluid (see Eqs. (1) and (2)). The unknowns of the system are the solid $\left(T_{\sigma}(x, t)\right)$ and fluid $\left(T_{\beta}(x, t)\right)$ temperature fields along the $x$ coordinate. Subscripts $\beta$ and $\sigma$ are referred to fluid and solid, respectively. Heat leakages to the external are neglected, and so the heat generation due to friction in the fluid. $h$ is the convective heat transfer coefficient, $\alpha$ is the fluid to total volume ratio (void fraction). The convective term, which is proportional to the local temperature difference between solid and fluid, couples the two equations.

The usual four steps of the AMR cycle are given by the application of Eqs. (3) to (6) to Eqs. (1) and (2). The initial condition is the isothermal condition between fluid, solid and environment. Magnetization and demagnetization processes are simulated by the imposition of the $\Delta T_{a d}$. The active material properties (specific heat $c_{p}\left(T_{\sigma}, B\right)$ and adiabatic temperature change $\Delta T_{a d}\left(T_{\sigma}, B_{\text {initial }}\right.$, $\left.B_{\text {final }}\right)$ ) are those of gadolinium, obtained from experimental data of Canepa et al. [15].

The pumping power required by the fluid to cross the regenerator is given by Eqs. (9) and (10), assuming a pump efficiency $h_{\text {pump }}=0.8$. The friction factor $f f$ is given by the Ergun correlation [14] Eq. (11) with the constant $C_{1}=180$ and $C_{2}$ $=1.8$ suggested by Kaviany [16]. $w$ is the actual fluid velocity in the regenerator (porous velocity).

$$
\begin{aligned}
& \frac{\partial T_{\beta}}{\partial t}=\frac{1}{\rho_{\beta} c_{\beta}}\left[\lambda_{\beta} \frac{\partial^{2} T_{\beta}}{\partial x^{2}}+\frac{\gamma}{\alpha} h\left(T_{\sigma}-T_{\beta}\right)-\frac{m_{\beta} c_{\beta}}{\alpha A} \frac{\partial T_{\beta}}{\partial x}\right], \\
& \frac{\partial T_{\sigma}}{\partial t}=\frac{1}{\rho_{\sigma} c_{\sigma}\left(T_{\sigma}, B\right)}\left[\lambda_{\sigma} \frac{\partial^{2} T_{\sigma}}{\partial x^{2}}-\frac{\gamma}{1-\alpha} h\left(T_{\sigma}-T_{\beta}\right)\right] .
\end{aligned}
$$

The heat transfer coefficient is evaluated by means of Wakao and Kaguei correlation [17] Eq. (12).

The global performance parameters describing the behavior of the AMR are: the refrigerating capacity $Q_{I N}$, the temperature span between the hot and the cold thermal source 
$\Delta T_{S P A N}=T_{H}-T_{C}$, the Coefficient of Performance $C O P$ and the second law efficiency $\xi$ defined as in Eqs. (13) and (16). The heat rejection is defined by Eq. (17). The cycle period $t_{C}$ is given by the sum of the hot and cold blow period, as demagnetization and magnetization are assumed instantaneous. The simulation starts from an isothermal initial condition forcing a $\Delta T_{S P A N}$ between the hot source (kept at the ambient temperature $T_{\text {ext }}$ ) and the cold source (kept $\Delta T_{S P A N}$ colder than the hot one) and then stops when the "steady" periodic regime is reached, that is the fluid and solid temperature fields repeat unchanged every cycle period $t_{C}$ (with a given tolerance of the order of $\left.10^{-6} \Delta T_{S P A N}\right)$. The system of equations is solved by a finite difference scheme implemented both in MATLAB and in MS Visual Studio.

The AMR cycle's boundary condition are reported below, together with the definitions of the system performances and parameters, for a generic cycle $\left(0<t<t_{C}\right)$.

Magnetization:

$$
\begin{gathered}
T_{\sigma}\left(x, 0^{+}\right)=T_{\sigma}\left(x, 0^{-}\right)+\ldots \\
\Delta T_{a d}\left(T_{\sigma}\left(x, 0^{-}\right), B_{M I N} \rightarrow B_{M A X}\right) .
\end{gathered}
$$

Hot blow boundary conditions:

$$
T_{\beta}(0, t)=T_{C},\left.\frac{\partial T_{\sigma}}{\partial x}\right|_{0, t}=0,\left.\frac{\partial T_{\sigma}}{\partial x}\right|_{L, t}=0 .
$$

Hot blow external controls:

$$
m_{\beta}(t)=m_{\beta}, \quad B(t)=B_{M A X} .
$$

Demagnetization:

$$
\begin{gathered}
T_{\sigma}\left(x,{ }^{t_{C}} /^{+}\right)=T_{\sigma}\left(x,{ }^{t_{C}} /_{2}^{-}\right)+\ldots \\
\Delta T_{a d}\left(T_{\sigma}\left(x,{ }^{t_{C}} / 2^{-}\right), B_{M A X} \rightarrow B_{M I N}\right) .
\end{gathered}
$$

Cold blow boundary conditions:

$$
T_{\beta}(L, t)=T_{H},\left.\frac{\partial T_{\sigma}}{\partial x}\right|_{0, t}=0,\left.\frac{\partial T_{\sigma}}{\partial x}\right|_{L, t}=0
$$

Cold blow external controls:

$$
m_{\beta}(t)=-m_{\beta}, \quad B(t)=B_{M I N} .
$$

Pumping power:

$$
\begin{aligned}
& W_{P U M P}=m_{\beta} \frac{\Delta P}{\rho_{\beta}} \frac{1}{\eta_{\text {pump }}}, \\
& \Delta P=f f \cdot \rho_{\beta} \frac{L}{d_{p}} \frac{(\alpha w)^{2}}{2},
\end{aligned}
$$

$$
f f=\frac{C_{1}}{R e_{p}}\left(\frac{1-\alpha}{\alpha}\right)^{2}+C_{2}\left(\frac{1-\alpha}{\alpha}\right) .
$$

Wakao and Kaguei correlation:

$$
N u_{p}=2+1.1 \operatorname{Re}_{p}^{0.6} \operatorname{Pr}^{1 / 3} \text {, }
$$

system performances:

$$
\begin{gathered}
\Delta T_{S P A N}=T_{H}-T_{C}, \\
C O P=\frac{Q_{I N}}{W_{M A G}+W_{P U M P}}, \\
\xi=\frac{C O P}{C O P_{C A R N O T}}=C O P \frac{\Delta T_{S P A N}}{T_{C}}, \\
Q_{I N}=\frac{1}{t_{C}} \int_{t_{C} / 2}^{t_{C}} m_{\beta} c_{\beta}\left(T_{C}-T_{\beta}(0, t)\right) d t,
\end{gathered}
$$

heat rejection:

$$
Q_{\text {OUT }}=\frac{1}{t_{C}} \int_{0}^{t_{C} / 2} m_{\beta} c_{\beta}\left(T_{\beta}(L, t)-T_{H}\right) d t .
$$

\section{RESULTS AND DISCUSSION}

A stability and accuracy analysis performed varying the discretization parameters time step $\Delta t$ and spatial step $\Delta x$ in different conditions, and taking into account a reasonable compromise between accuracy and the computational speed, lead to set the numerical steps to optimized values $\Delta x=2 \times 10^{-4} \mathrm{~m}$ and $\Delta t=1 \times 10^{-3} \mathrm{~s}$.

The standard set of parameters used in the preliminary analysis and in the parametric investigation, if not differently specified, is reported in Table 1. The parametric investigation is focused on the influence of the fluid mass flow rate and cycle frequency on the global performance of the device, operating as a refrigerator. The main figures of merit considered here are: $C O P, \xi, Q_{I N}$, as defined by Eqs. (14) to (16).

The fluid mass flow rate and the operating frequency can be related by the utilization factor $\Phi$ defined as in Eq. (18). The utilization factor is the ratio between the thermal capacity rate of the fluid and that of the solid.

$$
\Phi=\frac{m_{\beta} c_{\beta}}{M_{\sigma} \bar{c}_{\sigma}} \frac{t_{C}}{2} .
$$


Fig. 2 shows the non-dimensional useful effect $Q_{I N}{ }^{+}=Q_{I N} / Q_{I N, M A X}\left(Q_{I N, M A X}\right.$ evaluated at $\triangle T_{S P A N}=0{ }^{\circ} \mathrm{K}$ and $f=f_{0}=0.25 \mathrm{~Hz}$ ) the $C O P$, and the $\xi$ parameter with respect to $\Phi$.

Table 1. Reference values of the numerical parameters

\begin{tabular}{|l|c|}
\hline \multicolumn{2}{|c|}{ AMR process numerical simulation } \\
\hline Regenerator size $\left[\mathrm{cm}^{3}\right]$ & 62.5 \\
\hline Void fraction $\alpha[-]$ & 0.5 \\
\hline Total material mass $[\mathrm{kg}]$ & 0.250 \\
\hline Active material & $\mathrm{Gd}$, powder \\
\hline Mean particle size $[\mu \mathrm{m}]$ & 300 \\
\hline Fluid & Water \\
\hline$T_{\text {ext }}[\mathrm{K}]$ & 293 \\
\hline$B_{\mathrm{MAX}}, B_{\mathrm{MIN}}[\mathrm{T}]$ & $1.5,0.0$ \\
\hline Mass flow rate $\left[\mathrm{kgs}^{-1}\right]$ & $25 \cdot 10^{-3}$ \\
\hline Cycle frequency $f_{0}[\mathrm{~Hz}]$ & 0.25 \\
\hline
\end{tabular}

The curves at constant $\Delta T_{S P A N}$ are obtained increasing the fluid mass flow rate (keeping the frequency at $0.25 \mathrm{~Hz}$ ). The hot thermal source is at ambient temperature $T_{H}=T_{e x t}$ and the heat exchangers are ideal (the fluid leaves the heat exchangers and enters the regenerator at the respective source temperatures).

For a given $\Delta T_{S P A N}>0{ }^{\circ} \mathrm{K}$ the refrigeration capacity increases with $\Phi$, up to a limit and then it rapidly decreases. Furthermore, the $\Phi$ that guarantees the maximum $Q_{I N}{ }^{+}$decreases if the $\triangle T_{\text {SPAN }}$ increases. This behavior is reported also in Oliveira et al. [19]. The COP curves are very flat. For a given $\Delta T_{S P A N}$ there are many different
$\Phi$ values that ensure good behavior of the AMR as a refrigerator $\left(m_{\beta}=5 \mathrm{~g} / \mathrm{s}\right.$ gives about $\Phi=0.5$, and $m_{\beta}=26 \mathrm{~g} / \mathrm{s}$ gives about $\Phi=3$ ).

The $\xi$ curves are maximum shaped with respect to $\Phi$ and also to $\triangle T_{S P A N}$. There is an optimal operating $\triangle T_{S P A N}$ that minimizes the entropy production. The best performance calculated in this configuration is $\xi=0.29$ for $\Delta T_{\text {SPAN }}=20$ $\mathrm{K}$ and a $\Phi=0.75$. In this condition the $C O P$ is about 4 , but the refrigeration capacity is reduced to about $50 \%$ of the maximum reachable at the same $\Delta T_{\text {SPAN }}$.

Fig. 3 shows the same result of Fig. 2a with the normalization of $Q_{I N}$ with respect to the maximum refrigeration capacity $Q_{M A X}$ relative to each $\triangle T_{S P A N}$.

The optimal utilization decreases if $\Delta T_{S P A N}$ increases, and the refrigeration capacity is very sensitive to $\Phi$. A variation from the optimal utilization value of $+10 \%$ or $-20 \%$ causes a decrease in refrigeration capacity of about $20 \%$.

Fig. 4 shows the useful effect $Q_{I N}{ }^{+}$, the $C O P$, and the $\xi$ parameter with respect to operating frequency $f^{+}=f / f_{0}$. Each curve is given for the $\Phi$ value that maximizes the $Q_{I N}{ }^{+}$as shown in Fig. 2a. The system has constant MCM mass, and the temperature internal gradient (linked to Biot number $\mathrm{Bi}$ ) in the solid particles is neglected, so the increase in frequency results in a linear increase of $Q_{I N}{ }^{+}$. For fixed $\Phi$ the mass flow rate is also proportional to the frequency, so that the friction pressure losses change accordingly. On the other hand maximum shaped curves of $Q_{I N}{ }^{+}$ with respect to frequency should be expected
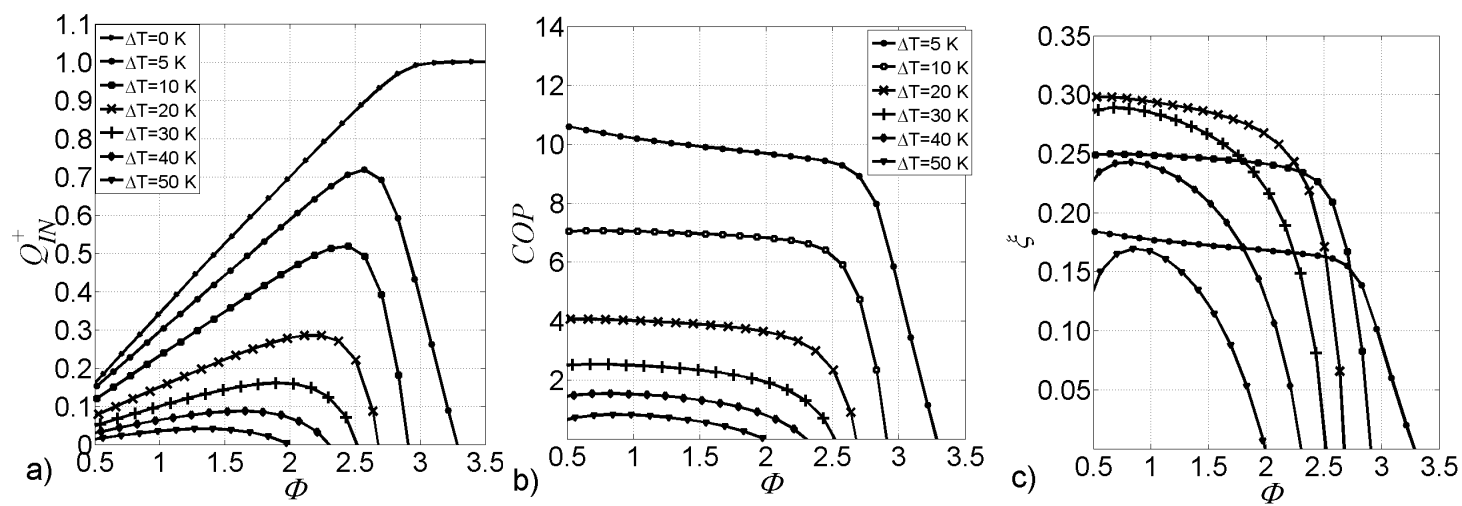

Fig. 2. a) $Q_{I N}{ }^{+}$, b) COP, c) $\xi$ of the AMR with respect to $\Phi$; the curves are given at constant temperature spans $\Delta T_{S P A N}$ and for the standard values of Table 1 
since, for very high frequency, bulk effects in the MCM particles should be accounted for as suggested by Engelbrecth et al. [20]. If the particle based $B i$ number is large $(B i>0.2)$, the effective convective heat transfer coefficient is reduced depending on the actual $B i$ and Fourier numbers, since the surface temperature of each particle becomes noticeably lower than the mean bulk temperature.

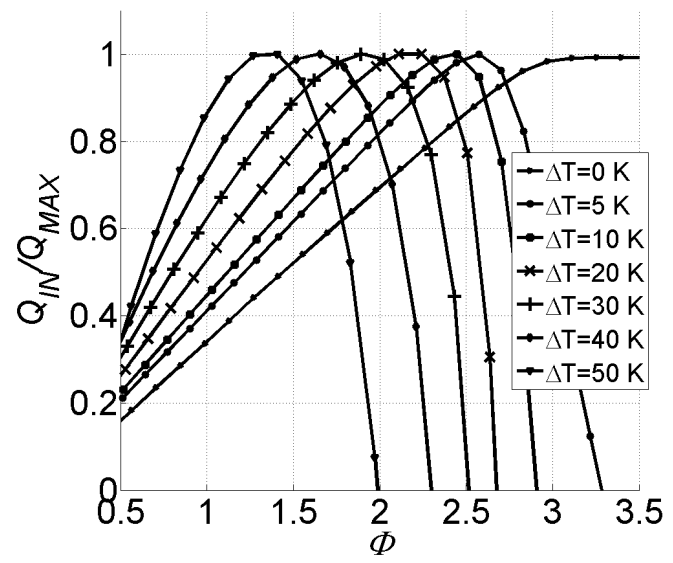

Fig. 3. Normalized refrigeration capacity for each $\Delta T_{\text {SPAN }} v$ s. utilization factor

For the given $\triangle T_{S P A N}$ and $T_{C}$, the curves of COP and $\xi$ follow the same trend (see Eq. (15)). The trend depends on the combined effects of heat transfer and friction irreversibility [21]. The heat transfer effect dominates at high $\Delta T_{S P A N}$ and low frequency, while friction effect dominates for small $\Delta T_{\text {SPAN }}$. Fig. $4 \mathrm{c}$ shows that for $\Delta T_{\text {SPAN }}=$ $5 \mathrm{~K}$ the heat transfer irreversibility is negligible and the $C O P$ trend is a continuously decreasing curve due to friction effects, while for $\Delta T_{S P A N}=40$ $\mathrm{K}$ the friction irreversibility is negligible and, as a consequence, COP is almost independent of $\mathrm{f}+$ (that is, approximately, of flow rate).

The maximum useful effect resulting from Fig. 2a compares well with experimental data reported by Zimm et al. [22] in a rotary system using Gd powder. They obtained specific cooling capacity per cc of Gd around $2.2 \mathrm{~W} / \mathrm{cc}\left(\Delta T_{\text {SPAN }} \sim\right.$ $0 \mathrm{~K}$ ) while the present simulation gives $2.3 \mathrm{~W} / \mathrm{cc}$.

\section{CONCLUSIONS}

A 1D dynamic numerical model of an AMR was developed and a performance parametric investigation that involves the operating parameters fluid mass flow rate and the operating cycle frequency (and so $\Phi$ ) was performed.

The parametric investigation shows that different optimal utilization values can be identified, with respect to temperature span, in order to maximize the performance of the AMR $\left(Q_{I N}, C O P\right.$ and $\left.\xi\right)$. The $C O P$ and $\xi$ curves as a function of operating frequency $f$ and $\Phi$ show a typical maximum shaped trend, which can be related to the two different entropy production terms: the heat transfer irreversibility and the friction irreversibility inside the AMR regenerator. Results show that an AMR device can operate with almost constant $C O P$ with different thermal loads, which can be met by properly tuning the
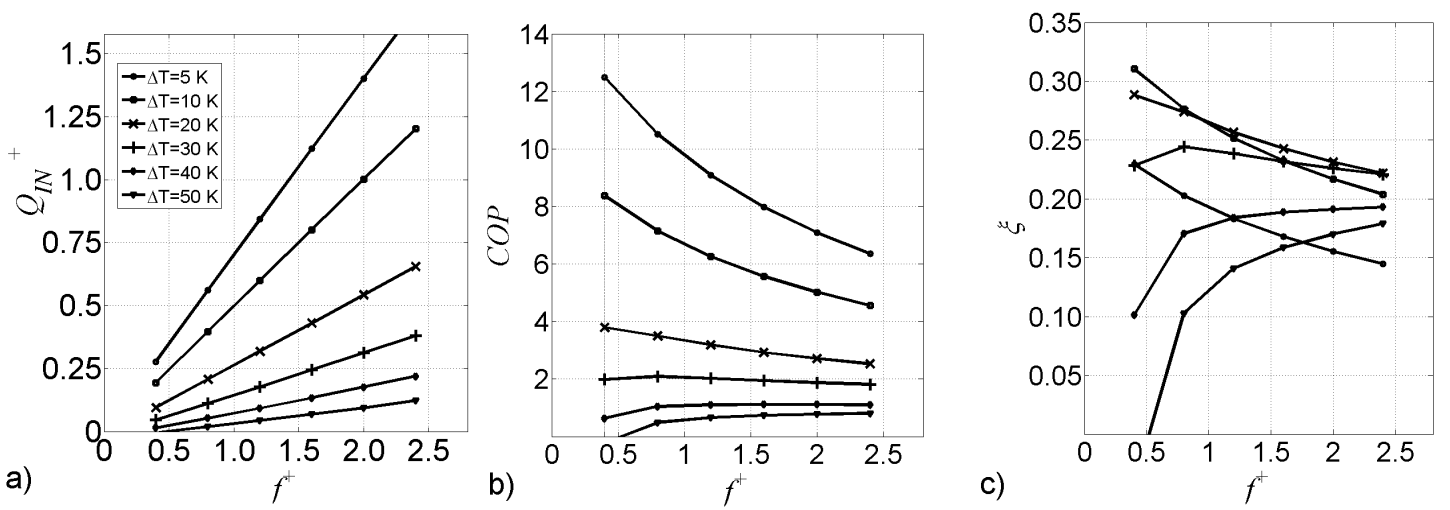

Fig. 4. a) $Q_{I N}{ }^{+}$, b) COP, c) $\xi$ of the AMR with respect to operating frequency; the curves are given at constant temperature spans $\Delta T_{S P A N}$ and for the optimal $\Phi$ given by a) 
utilization factor. This behavior could be exploited to achieve higher energy saving with respect to vapor compression systems, also in dynamic conditions by a proper control of the magnetic refrigerator device. Furthermore, the investigation on the operating frequency, in the low frequency field analyzed, shows that the refrigeration capacity can be increased by an increase in frequency with a very low effect on the $C O P$.

\section{ACKNOWLEDGEMENT}

This work was developed with the support of Ministry of University and Research (grant PRIN $2007 \mathrm{n}^{\circ} 2007893$ AC3).

\section{NOMENCLATURE}

symbol meaning and unit

$c \quad$ specific heat $\left[\mathrm{J} \mathrm{kg}^{-1} \mathrm{~K}^{-1}\right]$

$f \quad$ frequency $\left[\mathrm{s}^{-1}\right]$

ff friction factor [-]

$h \quad$ solid-to-particle convective heat transfer coefficient [ $\mathrm{W} \mathrm{m}^{-2} \mathrm{~K}^{-1}$ ]

$m \quad$ mass flow rate $\left[\mathrm{kg} \mathrm{s}^{-1}\right]$

$t_{C} \quad$ cycle time $[\mathrm{s}]$

$x \quad$ longitudinale coordinate $[\mathrm{m}]$

$w \quad$ porous velocity $\left[\mathrm{m} \mathrm{s}^{-1}\right]$

$A \quad$ regenerator cross section surface $\left[\mathrm{m}^{2}\right]$

AMR active magnetic regenerator

$B \quad$ magnetic field [T]

$B i \quad$ Biot number [-]

COP coefficient of performance

$L \quad$ regenerator length $[\mathrm{m}]$

$M \quad$ mass [kg]

$N u_{\mathrm{p}} \quad$ particle based Nusselt number [-]

$\mathrm{Pr} \quad$ Prandtl number

$Q \quad$ heat rate $[\mathrm{W}]$

$R e_{\mathrm{p}} \quad$ particle based Reynolds number [-]

$T$ temperature [K]

$W \quad$ mechanical power [W]

$\Delta P \quad$ pressure drop in the regenerator $[\mathrm{Pa}]$

$\Delta T_{\text {ad }} \quad$ adiabatic temperature change $[\mathrm{K}]$

$\alpha \quad$ void fraction [-]

$\gamma \quad$ specific heat transfer surface $\left[\mathrm{m}^{2} \mathrm{~m}^{-3}\right]$

$\eta \quad$ efficiency [-]

$\lambda \quad$ thermal conductivity [W $\left.\mathrm{m}^{-1} \mathrm{~K}^{-1}\right]$

$\xi \quad$ second law efficiency [-]

$\rho \quad$ density $\left[\mathrm{kg} \mathrm{m}^{-3}\right]$

$\Phi \quad$ utilization factor [-] subscripts

0 reference value

C of the cold source

$H \quad$ of the hot soruce

$\beta \quad$ of fluid phase

$\sigma \quad$ of solid phase

superscripts

$+\quad$ nondimensional

\section{REFERENCES}

[1] Engelbrecht, K.L., Nellis, G.F., Klein, S.A., Zimm, C.B. (2007). Recent developments in room temperature active magnetic regenerative refrigeration. $H V A C \& R$ Research, vol. 13, no. 4, p. 525-542

[2] Gschneidner, K.A.Jr., Pecharsky, V.K. (2008). Thirty years of near room temperature magnetic cooling: Where we are today and future prospects. International Journal of Refrigeration, vol. 31, no. 6, p. 945-961, DOI:10.1016/j.ijrefrig.2008.01.004.

[3] Yu, B., Liu, M., Egolf, P.W., Kitanovski, A. (2010). A review of magnetic refrigerator and heat pump prototypes built before the year 2010. International Journal of Refrigeration, vol. 33, no. 6, p. 1029-1060, DOI:10.1016/j. ijrefrig.2010.04.002.

[4] Engelbrecth, K., Nellis, G. F., Klein, S.A. (2007). Comparing modeling prediction to experimental data for active magnetic regenerative refrigeration systems. Proceedings of $2^{\text {nd }}$ International conference on Magnetic Refrigeration at room temperature, p. 349-357.

[5] Kawanami, T. (2007). Heat transfer characteristics and cooling performance of an active magnetic regenerator 2007. Proceedings of 2nd International conference on Magnetic Refrigeration at room temperature, p. 23-34.

[6] Sarlah, A., Poredos, A. (2007). Dimensionless numerical model for determination of magnetic regenerator's heat transfer coefficient and its operation. Proceedings of 2nd International conference on Magnetic Refrigeration at room temperature, p. 420-426.

[7] Bouchekara, H., Kedous-Lebouc, A., Dupuis, C., Allab, F. (2008). Prediction 
and optimization of geometrical properties of the refrigerant bed in an AMRR cycle. International Journal of Refrigeration, vol. 31, no. 7, p. 1224-1230, DOI:10.1016/j. ijrefrig.2008.02.007.

[8] Risser, M., Vasile, C., Engel, T., Keith, B., Muller, C. (2010). Numerical simulation of magnetocaloric system behaviour for an industrial application. International Journal of Refrigeration, DOI:10.1016/j.ijrefrig. 2010.02.004.

[9] Tagliafico, G., Scarpa, F., Canepa, F. (2010). A dynamic 1-D model for reciprocating active magnetic regenerator; influence of the main working parameters. International Journal of Refrigeration, vol. 33, p. 286293, DOI:10.1016/j.ijrefrig.2009.10.001.

[10]Petersen, T.F., Prynds, N., Smith, A., Hattel, J., Schmidt, H., Knudsen, H.H. (2008). Two-dimensional mathematical model of a reciprocating room-temperature active magnetic regenerator. International Journal of Refrigeration, vol. 31, p. 432-443, DOI:10.1016/j.ijrefrig.2007.07.009.

[11]Legait, U., Kedous-Lebouch, A., Rodont, L. (2009). Numerical simulation and analysis of the refrigerant bed behavior using fluent software. Proceedings of $3^{\text {rd }}$ International conference on Magnetic Refrigeration at room temperature, p. 295-302.

[12]Nielsen, K.K., Bahl, C.R.H., Smith, A., Pryds, N., Hattel, J. (2010). A comprehensive parameter study of an active magnetic regenerator using a 2D numerical model. International Journal of Refrigeration, vol. 33, no. 4, p. 753-764, DOI:10.1016/j. ijrefrig.2009.12.024.

[13] Nielsen, K.K., Tusek, J., Engelbrecth, K., Schopfer, S., Kitanovski, A., Bahl, C.R.H., Smith, A., Pryds, N., Poredos, A. (2011). Review on numerical modeling of active magnetic regenerators for room temperature. International Journal of Refrigeration, vol. 34, p. 603-616, DOI:10.1016/j. ijrefrig.2010.12.026.

[14]Ergun, S. (1952). Fluid flow through packed columns. Chemical Engineering Progress, vol. 48, p. 89-95.

[15]Canepa, F., Cirafici, S., Napoletano, M., Cimberle, M.R., Tagliafico, L.A., Scarpa, F. (2008). Ageing effect on the magnetocaloric properties of $\mathrm{Gd}, \mathrm{Gd}_{5} \mathrm{Si}_{1.9} \mathrm{Ge}_{2.1}$ and on the eutectic composition $\mathrm{Gd}_{75} \mathrm{Cd}_{25}$. Journal of Physics D: Applied Physics, vol. 41, DOI:10.1088/0022-3727/41/15/155004.

[16]Kaviany, M. (1995). Principles of Heat Transfer in Porous Media, 2nd edition: Springer, New York, DOI:10.1007/978-14612-4254-3.

[17] Wakao, N., Kaguei, S. (1982). Heat and mass transfer in packed bed. Gordon and Breach, New York.

[18]Nield, D.A., Bejan, A. (1998). Convection in porous media, Springer, New York.

[19]Oliveira, P.A., Trevizoli, P.V., Barbosa, Jr. J.R., Prata, A.T. (2009). Numerical analysis of a reciprocative active magnetic regenerator - part II. Proceedings of $3^{\text {rd }}$ International conference on Magnetic Refrigeration at room temperature, Des Moines, p. 289-294.

[20]Engelbrecth, K.L., Nellis, G.F., Klein, S.A., Boeder, A.M. (2005). Modeling active magnetic regenerative refrigeration systems. Proceedings of 1 st International conference on Magnetic Refrigeration at room temperature, p. 265-274.

[21]Bejan, A. (1982). Entropy generation through heat and fluid flow. John Wiley \& Sons, New York.

[22]Zimm, C., Boeder, A., Chell, J., Sternberg, A., Fujita, A., Fujieda, S., Fukamichi, K. (2006). Design and performance of a permanent magnet rotary refrigerator. International Journal of Refrigeration, vol. 29, p. 13021306, DOI:10.1016/j.ijrefrig.2006.07.014. 